\title{
Thinking: Lessons from John Dewey's How We Think
}

\author{
Moeketsi Letseka \\ Davison Zireva
}

\author{
University of South Africa \\ Morgenster Teachers College \\ E-mail: letsem@unisa.ac.za
}

Doi:10.5901/ajis.2013.v2n2p51

\begin{abstract}
In this article we draw on John Dewey's (1910) classic book How We Think to reflect on the absence of a culture of 'critical thinking' and/or 'reflective thinking' at Morgenster Teachers' College. 'Critical thinking' and/or 'reflective thinking' are central to John Dewey $(1916,1910)$ and Paulo Freire's $(2005,1995)$ teachings. But they are also embedded in the dialogues of Plato, for instance, The Republic, Meno, Euthyphro, Apology, and Protagoras, to mention a few. But data from focus group interviews conducted with final year students at Morgenster Teachers' College shows that pedagogical practices at the college are monologic or one-dimensional, which is not supportive of 'critical thinking' and/or 'reflective thinking'. Our contention in this article is that in teaching and learning it is essential for the students to be equipped with the skills to understand the world and what is in it. For such understanding to occur teachers should engage the students in philosophical inquiry and critical dialogue. Philosophical inquiry is most effective when it takes the form of dialogue between peers. But as Freire (1995) points out, true dialogue cannot exist unless the dialoguers engage in critical thinking. We recognise that Morgenster Teachers' College is an important institution with a mandate to produce teachers. It is therefore incumbent that the college shifts from monologic pedagogies, to pedagogiies that are anchored in philosophical inquiry, critical dialogue, 'critical thinking' and 'reflective thinking', which engender an understanding of the world and what is in it.
\end{abstract}

Keywords: Dewey, critical and/or reflective thinking, Morgenster Teachers' College, monologic pedagogy, Freire, critical dialogue

\section{Introduction}

In one of our articles we took issue with the pedagogical principles and practices at Morgenster Teachers' College (MTC) ${ }^{1}$, a private teachers' college of the Reformed Church in Zimbabwe (RCZ) in Masvingo, a town in south-eastern Zimbabwe. We found the college's pedagogical principles and practices to be monologic or one-dimensional. We worried that monologic pedagogy regards 'knowledge' as fixed bodies of facts that are out there and that must be transferred into the students' minds. We expressed concern that monologic pedagogy treats student teacher's as tabula rasa, a Latin phrase or expression for 'clean slates', 'empty vessels', or 'receptacles' that must be filled with the fixed bodies of facts, which are presumed to constitute 'worthwhile knowledge'. The presumption that fixed bodies of facts constitute 'worthwhile knowledge' is highly debatable (Freire, 1996, 2005; West, 2004; Gravett, 2001; Letseka, 1995; Dewey, 1910).

We surmised that monologic pedagogy has serious implications for teaching and learning and for theory and practice. On the one hand it is analogous to 'the banking concept of education', which Brazilian philosopher of education Paulo Freire cogently delineates in his celebrated book Pedagogy of the Oppressed. On the other hand monologic pedagogy is potentially indoctrinatory (Garrison, 1986; Macmillan, 1983; Snook, 1972a, 1972b, 1970). In the 1970s New Zealand philosopher of education Ivan Snook (1972a, p.3) argued that "once indoctrination is clearly understood, it will be obvious that it is reprehensible, although there will be disagreement as to why it is". While Snook $(1970$, p.56) was convinced that "indoctrination is a pejorative term", he was cautious that "far from it being the case that 'teaching' excludes 'indoctrination', there is a necessary or conceptual relationship between them" (Snook, 1972a, p.47). We worried that pedagogical practices at Morgenster are incapable of developing teachers that are initiated in the Socratic tradition of critical self-examination and critical dialogue, that is, teachers with critical and reflective thinking dispositions.

${ }^{1}$ Henceforth this shall be referred to as Morgenster. 
In this article, we draw lessons on John Dewey's (1910) classic book How We Think, to reflect on the philosophical nuances of the notions of 'critical thinking' and/or 'reflective thinking', and to speculate on how a deeper understanding of these notions can potentially impact teaching and learning environments where generally 'critical thinking' is not encouraged. It is our view that Dewey's book provides useful building blocks for theorising the notions of 'critical thinking' and/or 'reflective thinking', and that it is an invaluable resource for assisting initial teacher development educators in theorising their notions of 'critical thinking' and/or 'reflective thinking'. As Karl Popper (2002, pp.37-8) notes in his acclaimed book The Logic of Scientific Discovery, "theories are nets cast to catch what we call 'the world': to rationalise, to explain, and to master it. We endeavour to make the mesh ever finer and finer".

We proceed as follows. We start by sketching Dewey's conceptualisation of 'thinking', which he does wonderfully in chapter one of How We Think, "What is thought?". We follow this with a description and analysis of the data from focused group interviews that were conducted during the study on obstacles to critical thinking among third [final] year student teachers at Morgenster. The data suggests that educators at Morgenster are champions of monologic pedagogy. We then delineate probable causes to which the obstacles to 'critical' and/or 'reflective' thinking might be attributed. In the penultimate section of the article we comment on the pertinence of Dewey's teachings on 'thinking'. Our aim is to ascertain the implications for teaching and learning in environments such as Morgenster where 'critical thinking' and/or 'reflective thinking' are not encouraged. Our view is that Dewey's book remains pertinent to teaching and learning today as it was when it was first published in 1910. In the final section with provide some concluding remarks.

\section{John Dewey's conception of 'thinking'}

In How We Think John Dewey (1910) writes that so profuse and varied is our use of 'thinking' and 'thought' that it is not easy to define just what we mean by them. His intension in chapter one is 'to find a single consistent meaning'. It is worthwhile noting that Dewey's (1916, p.158) passions for 'thinking' and for the importance of the development of thinking skills is schools can again be found in Democracy and Education where he writes: "no one doubts, theoretically, the importance of fostering in school good habits of thinking". Dewey (1916, p.159) further argues that "thinking is the method of intelligent learning, of learning that employs and rewards mind". Thus "thinking originates in situations where the course of thinking is an actual part of the course of events and is designed to influence the result....The object of thinking is to help reach a conclusion, to project a possible termination on the basis of what is already given" (Dewey, 1916, p.154). And "since the situation in which thinking occurs is a doubtful one, thinking is a process of inquiry, of looking into things, of investigating". For Dewey then, "all thinking is research, and all research is native, original, with him who carries it on, even if everybody else in the world already is sure of what he is still looking for".

In "How we Think", Dewey (1910, p.1) argues that in the first place thought can be used loosely to refer to anything that 'comes to mind' or that 'goes through our heads'. In this regard "to think of a thing is just to be conscious of it in any way whatsoever". In this loose sense thinking signifies everything that is 'in our heads' or that 'goes through our minds'. Ennis (1964, p.599) calls this 'poor critical thinking'. Our view is that our responsibility as educators is to shun inclinations to promote 'poor critical thinking' among our students, but instead to strive towards 'thinking' in its critical, more reflective sense, or what Ennis calls 'good critical thinking'. Schafersman (1991, p.3) argues that critical thinking is critical inquiry. To that end critical thinkers investigate problems, ask questions, pose new answers that challenge the status quo, discover new information that can be used for good or ill, question authorities and traditional beliefs, challenge received dogmas and doctrines, and often end up possessing a power in society greater than their numbers. In another publication Schafersman $(1997$, p.4) posits that "the only way to escape both deception by others and the far more common trait of self-deception is to repeatedly and rigorously examine your basis for holding your beliefs. You must question the truth and reliability of both the knowledge claims of others and the knowledge you already possess".

For Dewey $(1910$, p.4), "thought denotes belief resting upon some basis, that is, real or supposed knowledge going beyond what is directly present. It is marked by acceptance or rejection of something as reasonably probable or improbable". Regarding 'reflection' Dewey $(1910, p .8)$ is unequivocal that "reflection thus implies that something is believed in (or disbelieved in), not on its own direct account, but through something else which stands as witness, evidence, proof, voucher, warrant; that is, as ground of belief'. In Democracy and Education Dewey (1916, p.150) contends that 'thought' or 'reflection' "is the discernment of the relation between what we try to do and what happens in consequence. No experience having a meaning is possible without some element of thought". Dewey (1910, p.6) defines 'reflective thought' as "active, persistent and careful consideration of any belief or supposed form of knowledge in the light of the grounds that support it and the further conclusions to which it tends". For Dewey (1910, p.57), "reflection is turning 
a topic over in various aspects and in various lights so that nothing significant about it shall be overlooked - almost as one might turn a stone over to see what its hidden side is like or what is covered by it". Dewey argues that in speaking of reflection, "we naturally use the words weigh, ponder, deliberate - terms implying a certain delicate and scrupulous balancing of things against one another. Closely related names are scrutiny, examination, consideration, inspection terms which imply close and careful vision". As shall become clear later when we broach into pedagogical principles and practices at Morgenster the above-mentioned discourse seems alien. We might add, it also seems like taboo.

Dewey (1910, p.10) picks out sub-processes which are involved in every reflective operation. These are: (a) a state of perplexity, hesitation, doubt; and (b) an act of search or investigation directed toward bringing to light further facts which serve to corroborate or to nullify the suggested belief. Perplexity forces us to carefully scrutinise what is before us; to look for evidence that will support belief in favour of either of the roads. For Dewey (1910, p.11), "thinking begins in what may fairly enough be called a forked-road situation, a situation which is ambiguous, which presents a dilemma, which proposes alternatives". He contends that "the origin of thinking is some perplexity, confusion, or doubt. Thinking is not a case of spontaneous combustion; it does not occur just on 'general principles'. There is something specific which occasions and evokes it" (Dewey, 1910, p.12). Perplexity, confusion, or doubt thus necessitates an act of search or investigation. And Dewey reminds us that "the next step is suggestion of some way out - the formation of some tentative plan or project, the entertaining of some theory which will account for the peculiarities in question, the consideration of some solution for the problem". Lest we forget, Grant \& Zeichner (1984, p.104) remind us that "much of what Dewey had to say on this matter was directed specifically at teachers and prospective teachers, and his remarks remain very relevant for those in the process of becoming teachers".

A question that might arise at this stage is: how pertinent are Dewey's teachings on 'thinking' and/or 'reflective thinking' to Morgenster? Our answer to that question is that Morgenster is a college whose core activity is initial teacher development. And if Dewey's teaching is directed at teachers and prospective teachers as Grant \& Zeichner (1984) argue, then the pertinence of his work to Morgenster cannot be overemphasised. In the next section we provide a brief background to the study conducted at Morgenster. We describe the sample of the students that comprised respondents during the focused group interview sessions, and we sketch some of their verbatim responses. What begins to emerge from the data is that the pedagogical principles and practices at Morgenster are incompatible with Freire's (1996) notion of education as the practice of freedom, dialogics and dialogue; Socrates' notion of critical self-examination or fearless speech - parrhesia (West, 2004), as well as Dewey's (1910) notion of 'reflective thinking' sketched above. We now briefly sketch the methodology we used to collect the data.

\section{Obstacles to critical/reflective thinking at Morgenster}

\subsection{Methodology}

\subsubsection{Focused group interviews}

In July 2011 one of the authors conducted focused group interviews of all final [third] year student teachers at Morgenster. We were convinced that focused group interviews would drill deeper into, and bring out the phenomenological hermeneutical lived experiences of the students (Gonzales, 2006; Lindseth \& Norberg, 2004; Eger, 1993a, 1993b), as well as permit us to draw on critical theory to probe the students experiences further (Nuyen, 1995; Held, 1990; Geuss, 1981). Martin Eger (1993a) argues that in educational practice a hermeneutic approach has to be advocated mainly to foster 'critical thinking'. He posits that by questioning the putative neutrality of reading a text, hermeneutics supports constructivist theories of knowledge and communication. By criticising over-dependence on formal methods, it highlights the linguistic component of the sciences - their shared, social elements. And by emphasising history, tradition, cultural perspectives, and by placing meaning at the centre of inquiry, hermeneutics aims to shore up in all scholarly activity an apparently declining human dimension (Eger, 1993a, p.1). In another publication Eger (1993b, p.304) asserts that as self-conscious interpretation hermeneutics becomes relevant in that "for each of the viewpoints selected, in each specific context, an interpretation of the object within that context is called for". Our view is that hermeneutics fosters philosophical dialogues reminiscent of those found in Plato's dialogues such as The Republic, Meno, Euthyphro, Apology, and Protagoras to mention a few. Gonzales (2006, p.313) contends that hermeneutics is "fundamentally and inescapably dialectical". Krabbe (2000, p.205) defines dialectic as "the practice and theory of 
conversations". He elaborates: "the primary purpose of most dialectic practices is not to convince or to persuade, but to attain at a truth of some sort by inquiry" (Krabbe. 2000, p.208).

Phenomenology aims to understand and interpret the meaning that subjects give to their everyday lives. Finlay $(2009$, p.6) notes that phenomenological researchers generally agree that their central concern is to return to embodied, experiential meanings. Phenomenological researchers aim for fresh, complex, rich descriptions of a phenomenon as it is concretely lived. In this regard phenomenology has been described as a low-hovering, in-dwelling, meditative philosophy that glories in the concreteness of person-world relations and accords lived experience, with all its indeterminacy and ambiguity, primacy over the known (Wertz, 2005, p.175). Indeed Bradbury-Jones., Sambrook., \& Irvine (2009) argue that focus groups are congruent with phenomenological research and propose that group interviews in phenomenology are beneficial because they stimulate discussion and open up new perspectives.

Combining phenomenology and hermeneutics, as in phenomenological hermeneutical method for researching lived experience broadens and enhances the scope of focused group interviews. Lindseth., \& Norberg (2004, p.151) argue that phenomenological hermeneutical investigations are about the meaning of lived experience. While they can be used to affect meaning of lived experience as understood by the interpreter, they caution that it is not only the interpreter that interprets the text. But that the text also interprets the interpreter. Thus the aim of phenomenological hermeneutical method is to disclose truths about the essential meaning of being in the life world. Researchers should not expect to find a single fundamental truth because the whole truth can never be fully understood. Instead, through a phenomenological hermeneutical journey researchers should search for possible meanings in a continuous process. It is our conviction that by engaging with small groups of students in focused group interviews a phenomenological hermeneutical method helped us to "search for possible meanings in a continuous process".

'Critical theory' has its origins in the Frankfurt School where it is associated with the following first generation theoreticians of the school: Max Horkheimer, Theodor Adorno, Herbert Marcuse, Leo Lewenthal, Frederick Pollock, and Eric Fromm. Jürgen Habermas is regarded as a second generation member of the Frankfurt School who is credited for recasting the notion of critical theory in his recent work in philosophy and sociology" (Held, 1990, p.15). Held (1990, p.183) argues that 'critical theory's' "method of procedure is immanent criticism, which confronts existence in its historical context, with the claims of its conceptual principles, in order to criticise the relation between the two and thus transcend them. For Geuss (1981, p. 2), 'critical theory' has always been portrayed as "a reflective theory which gives agents a kind of knowledge inherently productive of enlightenment and emancipation".

\subsubsection{The interviews}

The field interviewer interviewed three groups of between six and seven students per group. The interviews lasted between 45 minutes to one hour. The interview process focused on seven key issues: perceptions of the influence of religion on critical thinking dispositions; perceptions of negative self concept with respect to critical thinking dispositions; the influence of monologic pedagogy and its implications for the development of critical thinking dispositions; lack of opportunities for experiential time on critical thinking dispositions; the influence of a closed political system on the development of critical thinking dispositions; the influence of gerontocratic orientations on critical thinking dispositions, and the influence of femininity orientations on critical thinking dispositions.

The respondents were asked for their views on philosophy of education, and on their performances in philosophy of education assignments. If they did not do well they were asked to reflect on what might have contributed to their poor performance. In the second stage the respondents were asked to share views and opinions on the presentation of lectures in philosophy of education and to comment on how it might have impacted on their attitudes, either negatively or positively, towards philosophy of education. Given that the principal object of philosophy of education is the disciplined analysis, criticism and construction of arguments, the respondents were asked for their views on whether education should be a means for preparing individuals to play a critical role in social and political change. The primary issues about which the respondents were asked to express their views entailed perceptions on the influence of religion on critical thinking dispositions; the conditions in the college and whether they might be attributed to negative self concept with respect to critical thinking dispositions; the influence of monologic pedagogy and how it might impact on the development of critical thinking dispositions; absence of opportunities for experiential [research and seminars] time on critical thinking dispositions; the influence of gerontocratic orientations; the influence of a politically closed system, and the influence of femininity orientations. In closing, the respondents were asked for their views on factors they might attribute to stifling the development of their critical thinking dispositions. 
The interviews were audio-taped, transcribed, and described using the respondents' verbatim responses. Most qualitative researchers recognise that interviews should be recorded and transcribed in order to document transparency and to facilitate analysis and review of data after the interviews have taken place (Brod., Tesler., \& Christensen, 2009). Kidd \& Parshall $(2000$, p.298) argue that audiotape is often easier for a transcriptionist to work with than videotape. Of crucial importance though, audio-taping helps researchers remedy common, everyday memory problem (Vemuri., Schmandt., Bender., Tellex., \& Lassey, 2004). Vemuri et al (2004, p.401) argue that while retrieving any information that triggers the memory of the event is sufficient, finding the exact information is necessary, which is why audio-taping is so important to qualitative researchers.

\subsubsection{Consideration of the code of research ethics}

Given that the study was conducted under the auspices of the University of South Africa (UNISA)'s Research Directorate the researchers were bound to comply with the university's code of research ethics as outlined in UNISA Policy on Research Ethics (2007). The policy states that "participants are autonomous agents who have a right to choose whether or not to be part of the research". Furthermore: "researchers should not infringe the autonomy of participants by resorting to coercion, undue influence or the promise of unrealistic benefits" (UNISA, 2007, p.11), because "autonomy requires that individuals' participation should be freely given, specific and based on informed consent" (UNISA, 2007, p.10). We developed an informed consent form explaining in detail the university's code of research ethics which was read out to the respondents before the interviews started so that there was common understanding on the rules of engagement. Upon ensuring that the respondents fully understood what they were consenting to, they were then requested to sign the voluntary consent form. The policy states that "measures to ensure privacy, anonymity and confidentiality of participants, as well as any risk of breach of confidentiality and anonymity should be explained. If data and identity provided by participants in group discussions cannot be kept anonymous and confidential, this should also be disclosed" (UNISA, 2007, p.13). We recognised very early that by their very nature focus group interviews cannot guarantee confidentiality and non-disclosure of the information. To that end the respondents were asked to treat the informed consent form as proxy of non-disclosure agreement that bound them to the ethical principles of confidentiality and nondisclosure of any information regarding the interviews. Concomitantly the interviewer assured the respondents that we would not disclose their identities during compilation of the study's preliminary report as well as during dissemination of the study's findings. Instead non-traceable pseudonyms such as 'respondent 1', 'respondent 2', or 'respondents' would be used.

\section{Brief look at some of the findings}

\subsection{On perceptions of the influence of religion on critical thinking dispositions}

One respondent told the interviewer:

"Try critical discussion on religious issues here at Morgenster College and you'll get deferred".

It became clear from group sessions that an element of coercion existed at the college for students to conform to certain religious doctrines. And from the above response it could be gleaned that deviation from the norm would have serious consequences. We argue that to compel students to conform to fixed and inflexible rules is tantamount to indoctrination (Garrison, 1986; Macmillan, 1983; Snook, 1972a, 1972b, 1970). As Snook (1970, p.70) puts it, "the essence of indoctrination lies in the method. Its evil lies in the intention". He further argues that "to the degree that the learner becomes unfit to consider the matter on its merit, indoctrination has occurred. To the extent that a person takes steps to bring this about, indoctrination is morally wrong".

\subsection{On negative self concept with respect to critical thinking dispositions}

In response to this category some of the respondents showed evidence of negative self-concept with regard to their capacity to freely comment on issues that are in the public domain. For instance, some students doubted their capacity to comment on, or to give authoritative opinions on ideas of renowned African leaders. For instance, one respondent stated her views as follows: 
"When I size myself against Nyerere, I am nothing intellectually to critique his ideas".

And

"I don't think I will ever become a philosopher - I don't have the intelligence".

"Look at us, just 'O' Level school leavers".

\subsection{On the influence of monologic pedagogy and its implications for the development of critical thinking dispositions}

The category elicited the following responses:

"Some lecturers just come and read notes to us".

"Sometimes you feel that you should reproduce what the 'fundis' give to you".

These responses are reminiscent of the 'banking concept of education' that Paulo Freire succinctly articulates in his acclaimed book Pedagogy of the Oppressed. Freire (1996, p.53) argues that in the 'banking concept' education becomes "an act of depositing, in which the students are depositories and the teacher is the depositor. Instead of communicating, the teacher issues communiqués and makes deposits which the students patiently receive, memorise, and repeat". According to this logic "knowledge is a gift bestowed by those who consider themselves knowledgeable upon those whom they consider to know nothing. Projecting an absolute ignorance onto others, a characteristic of the ideology of oppression, negates education and knowledge as processes of inquiry" (Freire, 1972, p.53). But as Letseka $(1995$, p.295) cautions, the "so-called learning where the flow of information is one-dimensional, that is, where one element or subsystem plays a major or dominant role in the operation of the system as a whole, cannot, logically speaking, be called education. Within philosophy of education discourse such an 'interaction' qualifies as indoctrination".

\subsection{On the absence of opportunities for experiential time on critical thinking dispositions}

In response to this category one respondent lamented that:

"Our timetable is packed more than the primary school timetable".

Other respondents informed the interviewer:

"We hand in assignments when they are still hot [we work on the assignments in the night when the due date for submission is the next day]".

"There is no time to digest what you are told".

"We have no time to think about the notes given to us".

"In other areas we reproduce the notes due to lack of time

The question we ask is, is 'reproducing the notes' a manifestation of learning? Our answer is an unequivocal 'No'. As Paulo Freire (2005, p.40) points out, "to study is to uncover; it is to gain a more exact comprehension of an object; it is to realise its relationship to other objects". To that end teaching cannot be a "mechanical transference from which results machinelike memorisation". Moreover, "critical study correlates with teaching that is equally critical, which necessarily demands a critical way of comprehending and of realising the reading of the word and that of the world, the reading of text and of context".

\subsection{On the influence of a closed political system on the development of critical thinking dispositions}

This category elicited the following responses: 
"Follow what you are told and have peace - be critical and philosophical and get into pieces".

Another respondent gave an impression of an individual living in a highly censored political environment, and who has, necessarily resigned to self-censoring herself:

"About issues concerning politics, I am not prepared to comment"

When asked about their reluctance to get involved in political issues one respondent made the following comments:

"I am afraid you may not finish the course".

"Why would one dice with trouble".

It is Letseka's (1995, p.289) contention that "closed systems would be those that cannot import energy". In social theory and political practice systems that qualify as 'closed' are dictatorial, military, totalitarian, autocratic, tyrannical and other single-handed forms of government. It is our view that the college is a closed system as a result of the political environment in which it exists, and which it is incapable of changing.

\subsection{On the influence of gerontocratic orientations on critical thinking dispositions.}

We pointed out in our description of the sample above that 12 of the respondents or 66 per cent came from rural areas while 8 or 34 per cent came from urban areas. We suggested that this was probably an important indicator that should shed light on the influence of gerontocracy on critical thinking dispositions. The Oxford English Dictionary defines gerontocracy as 'government by a council of elders'/ 'a governing body consisting of old people'/ 'a state or government in which old people rule'. We do not presume there is anything fundamentally wrong with gerontocracy. In fact some western theorists have written about gerontocracy as a useful unit of socio-political and cultural analysis in oral cultures. For instance, Canadian philosopher of education Kieran Egan (1992, p.641) observes that in oral cultures elders are of such considerable socio-political and cultural importance in that they are deemed "qualified to speak authoritatively on public matters and to mediate on socio-political and cultural issues because they articulate the meaning of life". Similarly Yale University political scientist Robert Dahl $(1998, p .10)$ notes that tribal elders "see themselves as about equal in being well qualified to have a say in governing the group", while Nelson Mandela (1995, p.24) argues that the elders are "wise men who retained the knowledge of tribal history and custom in their heads and whose opinions carried great weight". The issue of major contestation with gerontocracy is that invariably the 'elders' are males. Feminist critics have charged that most oral cultures are patriarchal and notorious for excluding women from public decision-making structures and forums. American feminist political philosopher Susan Moller Okin (1999) did not mince her words in asserting that most of the world's traditions and cultures "are quite distinctly patriarchal".

Upon probing the respondents further on the possible influence of gerontocracy on critical thinking dispositions the probes yielded the following responses:

"Whatever elders say is indisputable".

One respondent expressed total frustration on the issue of 'whose knowledge counts and why'? She lamented:

"You get current information on the internet but you are told that experience counts most".

"Old people say, 'Takabva nako kumhunga hakuna ipwa' [I have experienced a lot in this area so get it from me'].

In a seemingly inevitable surrender to the elders' monopoly of 'knowledge' and other 'ways of knowing' one respondent informed the interviewer:

"Keep quiet, old people do not make mistakes".

"Philosophise with age-mates, but not among the elders". 


\subsection{On the Influence of femininity orientations on critical thinking dispositions.}

Some female respondents shared their experiences of induction and socialisation by the elderly women into a wide spectrum of gendered roles and societal expectations, all of which help reinforce the 'distinctly patriarchal' nature of most cultures to which Okin (1999) referred above. For instance:

"When one gets married, one's aunts advise her not to be argumentative in the home".

"At 'kitchen parties' older women advise us not to be critical in the home".

Similarly critical dialogue which we identified as central to the work of Paulo Freire $(2005,1996)$ above can at best be described as taboo among some of the married female respondents:

"A good woman is one who obeys".

"In-laws do not like critical women".

"Your critiquing should end at college, not in the home".

"Your husband would think you are big headed because you have been to college".

One of the male respondents endorsed this patriarchal mindset when he declared:

"I would not like to marry a woman who would engage me in debates".

\section{The pertinence of Dewey's teachings on 'thinking' in contemporary settings}

It should be clear by now that our starting point is that thinking, whether it is 'critical' and/or 'reflective' thinking, is sine qua non to teaching and learning. Grant \& Zeichner $(1984$, p.104) argue that in any social setting, and the school is no exception, there exists' a taken-for-granted definition of everyday reality in which problems, goals, and the means for their solution become defined in particular ways. They contend that as long as everyday life continues without interruption, this reality is perceived to be unproblematic. Teachers who are unreflective about their work uncritically accept this everyday reality in schools and concentrate their efforts on finding the most effective and efficient means to achieve ends and to solve problems that have largely been defined for them by others. It is our view that in How We Think Dewey is making a case for teachers and prospective teachers to be 'critical' and/or 'reflective' thinkers. The need for 'critical' and/or 'reflective' thinking is fairly easy to fathom. As Schafersman (1997, p.2) points out, "critical thinking is perhaps the most important skill a student can learn in school and college, since if you master its skills, you know how to think successfully and reach reliable conclusions, and such ability will prove valuable in any human endeavour, including the humanities, social sciences, commerce, law, journalism, and government, as well as in scholarly and scientific pursuits". The other important consideration is that generally 'critical' and/or 'reflective' thinkers are open-minded. Open-mindedness as used here "refers to an active desire to listen to more sides than one, to give full attention to alternative possibilities, and to recognise the possibility of error even in the beliefs that are clearest to us" (Grant \& Zeichner, 1984, p.105). Thus to the open-minded, critical and/or reflective education practitioners, what appears on the surface to be "everyday reality is only one of many possible alternatives". As for Dewey (1910, p.58), no argument is needed to point out that "the intellectual [as distinct from the moral] end of education is the formation of careful, alert, and thorough habits of thinking".

Knight \& Collins (2010) make a compelling case for "the power of philosophical inquiry", which we think is deeply embedded in Dewey's articulation of 'critical thinking' and/or 'reflective thinking' as sketched above. Knight \& Collins (2010, p.309) define philosophical inquiry as "the questioning of underlying assumptions, assumptions whose truth or falsity cannot be decided by appeal to experiment and observation". They argue that philosophical inquiry "is directed at issues whose resolution depends less on data gathering than on the formulation of arguments". It is their contention that if students are to develop an understanding of the world and what is in it, then as teachers we must engage them in philosophical inquiry. The reason for this is that philosophical inquiry leads to understanding, which they conceive of as "an active process, involving the construction of reasons and meanings" (Knight \& Collins, 2010, p.307). Knight \& Collins (2010, p.310) argue that "the more children engage in philosophical inquiry, the more likely it is that they will come to care for truth". Our view is that the same argument applies to mature adult learners like those at Morgenster. Citing Lipman (1985), Knight \& Collins (2010, p.315) argue that philosophical inquiry is most effective when it takes the form of dialogue 
between peers. By dialogue they mean "talking which is disciplined by the rules of logic". They contend that "the most direct link to thinking is talking - students can voice their thoughts effectively even if they have trouble doing so in writing". Notice the similarity here with Paulo Freier's emphasis on dialogue. As Freire $(1996$, p.73) puts it, "true dialogue cannot exist unless the dialoguers engage in critical thinking - thinking which discerns an indivisible solidarity between the world and the people and admits of no dichotomy between them- thinking which perceives reality as process, as transformation, rather than as a static entity - thinking which does not separate itself from action, but constantly immerses itself in temporality without fear of the risks involved".

\section{Conclusion}

What we have tried to do in this article is to draw lessons from John Dewey's (1910) teachings on 'thinking' in his classic book How We Think, with a view to reflecting on the implications of the absence of a culture for 'critical thinking' and/or 'reflective thinking' at Morgenster. 'Critical thinking' and/or 'reflective thinking' are central to the teachings of both Dewey $(1916,1910)$ and Freire $(2005,1995)$. They can also be found in the many dialogues of Plato such as The Republic, Meno, Euthyphro, Apology, and Protagoras, to mention a few. Yet as the data from focus group interviews with final year teacher education students at Morgenster shows, the pedagogical principles and practices at the college are not supportive of 'critical thinking' and/or 'reflective thinking'. This is an unfortunate situation given that in the educative process, that is, in teaching and learning, it is essential that teachers equip the students with the skills to understand the world and what is in it. Understanding here is taken to mean "an active process, involving the construction of reasons and meanings". In order for understanding to occur teachers must engage the students in critical dialogue and philosophical inquiry. Philosophical inquiry is most effective when it takes the form of dialogue between peers. By dialogue we mean "talking which is disciplined by the rules of logic". We showed that for Freire (1995), "true dialogue cannot exist unless the dialoguers engage in critical thinking". In closing we want to acknowledge that Morgenster is an important higher education institution that is mandated to produce teachers. Which is why it is of utmost importance that the college shifts from monologic pedagogies to pedagogical approaches that are grounded in 'philosophical inquiry', 'critical dialogue', 'critical thinking' and 'reflective thinking'. That is, pedagogical approaches that engender a deeper understanding of the world and what is in it.

\section{References}

Bradbury-Jones, C., Sambrook, S., \& Irvine F. (2009) The phenomenological focus group: an oxymoron? Journal of Advanced Nursing, 65(3), pp.663-671.

Dewey, J. (2001) Democracy and Education, Pennsylvania State University Press: Philadelphia.

Dewey, J. (1910) How We Think, D. C Heath \& Co Publishers: Chicago.

Eger, M. (1993a) Hermeneutics as an approach to science: Part I, Science \& Education 2:pp.1-29.

Eger, M. (1993a) Hermeneutics as an approach to science: Part II, Science \& Education, 2, pp.303-328.

Ennis, R. (1964) A definition of critical thinking, The Reading Teacher, 17 (8), pp.599-612.

Finlay, L. (2009) Debating phenomenological research methods, Phenomenology \& Practice, 3 (1), pp. 6-25.

Freire, P. (2005) Teachers as Cultural Workers: Letter to those who Dare Teach, Westview Press: Boulder, Colorado.

Freire, P. (1996) Pedagogy of the Oppressed. Penguin Books: London.

Garrison, J. W. (1986) The paradox of indoctrination: a solution, Synthese, 68 (2), pp.261-273.

Geuss, R. (1981) The Idea of a Critical Theory: Habermas and the Frankfurt School, Cambridge University Press: Cambridge.

Gonzales, F. J. (2006) Dialectic and dialogue in the hermeneutics of Paul Ricoeur and H. G. Gadamer, Continental Philosophy Review, 39, pp.313-354.

Grant, C \& Zeichner, K. (1984) Preparing for Reflective Teaching, Allyn and Bacon: Boston.

Gravett, S. (2001) Adult Learning. Pretoria: Van Schaik.

Held, D. (1990) Introduction to Critical Theory: Horkheimer and Habermas, Polity Press: Cambridge, UK.

Knight, S., \& Collins, C. (2010) Enlivening the curriculum: The power of philosophical inquiry, Theory and Research in Education, 8(3), pp. 305-318.

Krabbe, E. C. W. (2000) Meeting in the house of Callias: rhetoric and dialectic, Argumentation, 14, pp.205-217.

Letseka, M. (1995) Systems theory and educational discourse, in Philip Higgs (ed) Metatheories in Philosophy of Education, Heinemann: Johannesburg.

Lindseth, A., \& Norberg, A. (2004) A phenomenological hermeneutical method for researching lived experience, Scandinavian Journal of Caring Sciences, 18, pp.145-153.

Lipman, M. (1985) Philosophy and the cultivation of reasoning, Thinking, 5(4), pp. 31- 41. 
Macmillan, C. J. B. (1983) On certainty and indoctrination, Synthese, 56 (3), pp.363-372.

Mandela, N (1995) Long Walk to Freedom: The Autobiography of Nelson Mandela Abacus: London.

Nuyen, A. T. (1995) Critique of ideology: hermeneutics or critical theory, Human Studies, 17, pp.419- 432.

Okin, S. M. (ed) (1999) Is Multiculturalism Bad for Women? Princeton University Press: New Jersey.

Popper, K. (2002) The Logic of Scientific Discovery, Routledge: London.

Schafersman, S. (1997) An Introduction to Science: Scientific Thinking and the Scientific Method, retrieved from: http://www.muohio.edu/ schafesd/documents/intro-to-sci.htmlx 6 January 2013.

Schafersman, S. (1991) An Introduction to critical thinking, retrieved from http://facultycenter.ischool.syr.edu/ 6 January 2013.

Snook, I. A. (1972a) Indoctrination and Education, Routledge \& Kegan Paul: London.

Snook, I. A. (ed) (1972b) Concepts of Indoctrination: Philosophical Papers, Routledge \& Kegan Paul: London.

Snook, I. A. (1970) The concept of indoctrination, Studies on Philosophy and Education, 7(2), pp.65-108.

Wertz, F. (2005) Phenomenological research methods for counselling psychology, Journal of Counselling Psychology, 52 (2), pp. 167177.

West, C. (2004) Democracy Matters: Winning the Fight against Imperialism, Penguin Press: New York. 